\title{
Crise e neoliberalismo no capitalismo setentrional
}

\author{
Resenha de Tempo comprado: a crise adiada do \\ capitalismo democrático, de Wolfgang Streeck. São \\ Paulo: Boitempo Editorial, 2018
}

\author{
Rafael Marino \\ rafael.marino50@gmail.com \\ (Universidade de São Paulo, São Paulo, Brasil) \\ Daniela Costanzo \\ danicosper@gmail.com \\ (Universidade de São Paulo, São Paulo, Brasil)
}

DOI: http://dx.doi.org/10.11606/issn.2318-9800.v25i1p133-148

\begin{abstract}
A partir de uma longa visada, o livro de Wolfgang Streeck, Tempo comprado: a crise adiada do capitalismo democrático, pretende explorar as determinações essenciais da passagem, em meio a crises fiscais e financeiras, de um capitalismo democrático, baseado em um Welfare State e instituições políticas keynesianas, para um capitalismo neoliberal, no qual um regime econômico neo-hayekiano caracterizado essencialmente por uma máxima desregulamentação econômica e pela proteção frente a qualquer normatização ou correções políticas de massa - impõe um mercado que se pretende imune a qualquer tipo de intervenção democrática. Nesse sentido, uma das teses mais fortes do economista alemão é a de que a crise de 2008 marcaria o possível fim dos adiamentos de conflitos decorrentes da crise do capitalismo democrático, ocorrida na década de 1970. Falamos em longa visada, pois o seu estudo abarca, pelo menos, as transformações do capitalismo e a marcha do capital desde os fins da década de 1960 até a década de 2010. O que acaba por tornar-se um respiro benfazejo em meio às análises políticas e econômicas presentes no mercado das ideias, fortemente pautadas por certo imediatismo e por estudos de curto fôlego.
\end{abstract}


A base material com que Streeck lida é a do capitalismo de países ricos notadamente nações europeias, como Alemanha e França, além de nações de outros continentes, como Estados Unidos da América e Japão - "como unidade multifacetada, constituída pela interdependência, em meio à dependência coletiva dos Estados Unidos, quanto pelas peculiaridades dos conflitos internos e dos problemas de integração sistêmica” (Streeck, 2018, p. 12). ${ }^{1}$ A fundamentação teórica que lança mão para cuidar deste material é um amálgama entre marxismo, renovado pela assim chamada novas leituras de Marx (Elbe, 2013), teoria crítica frankfurtiana das crises e as formulações de Michal Kalecki e Karl Polanyi. O que não deixa de também chamar a atenção, dada a preponderância de pesquisas e trabalhos fortemente especializados e centrados em particularismos formais e subjetivos, seja de atores ou mesmo de instituições políticas, nas ciências sociais, principalmente na economia e na ciência política. Não obstante a sua aproximação destas teorizações amalgamadas, Streeck não deixa de ver nelas algumas limitações frente ao material por ele enfrentando, o que serve, sobretudo, para o aperfeiçoamento daquele instrumental e não seu abandono.

Quanto às suas divisões internas, o livro é composto por seis partes, sendo quatro capítulos, um prefácio à segunda edição, de 2015, e uma introdução, os quais procuraremos explorar, mesmo que sumariamente e sem necessariamente seguir a sua ordenação.

No prefácio, Streeck volta-se para a discussão de seus pressupostos teóricos, suas escolhas de caminhos durante a apresentação de seu argumento e a exposição sucinta de alguns de seus achados de maior relevância. Quanto ao primeiro elemento, o referido amálgama crítico e neomarxista permite que o economista alemão veja o capitalismo como uma sequência de crises imanentes ao processo de valorização do valor; o mercado como algo reposto empiricamente a partir do entrecruzamento entre ação estratégica e as lutas distributivas coletivas "nos mercados expandidos, impulsionado por uma dinâmica relação de troca entre espaços de classes e de interesses, de um lado, e de grupo organizados e instituições políticas, de outro, com particular consideração do problema da reprodução financeira do Estado" (Streeck , 2018, p. 9) e o capital como uma espécie de sujeito capaz de assumir estratégias complexas para levar a bom termo sua valorização e expansão. Estratégias as quais operam, por exemplo, via greve de investimentos, como as antevistas por Kalecki

1 À vista disto, não há base para Cariello (2019) chamá-lo de eurocêntrico, como se Streeck, espertamente, não tivesse revelado a base a partir da qual estuda mudanças importantes do capitalismo. Na verdade, Cariello é que nitidamente procura uma forma de atacar as posições de Streeck para elogiar as pretensas qualidades distributivas e civilizatórias do capitalismo. Que as pessoas tenham mais alguns dólares hoje do que o que ganhavam três décadas atrás, qualquer estudo empírico revela, mas Cariello esquece de dizer que as jornadas de trabalho no mundo voltaram a ter um nível de destrutividade poucas vezes visto e que, apesar de ganhos miseravelmente maiores, as desigualdades continuam aumentando de maneira gritante (Cf. Streeck, 2018, p.100; Piketty, 2014). 
(1943), para quem os capitalistas, vendo o pleno emprego e o poderio da classe trabalhadora aumentado, utilizariam-se daquele expediente para o enfraquecimento dos trabalhadores e para a extenuação do poder do Estado. Nesse bojo, o mercado e suas estratégias políticas, deixados por eles mesmos, sem a resistência da classe trabalhadora e de políticas voltadas para desmercadorização, poderiam, tendencialmente, tornar-se um moinho satânico com potencial para destruir a civilidade e a sociedade (cf. Polanyi, 2000).

Já em relação às trilhas percorridas por Streeck, três parecem ser os elementos essenciais. Em primeiro lugar, o capitalismo democrático dos países ricos a que se refere é visto pelo economista como um período de excepcional e específica estabilidade, construída politicamente a partir de uma elite tecnocrática, frustrada com os anos 1930 e "fundada em uma economia de guerra (...) centrada no Estado, que tinha uma coisa em comum com todas as linhas partidárias: profunda e experimentada dúvida sobre a viabilidade e sustentabilidade do livre mercado capitalista" (Streeck, 2018, p. 16). Havia, portanto, uma crise de legitimidade capitalista que exigiu que os capitalistas aceitassem um regime social democrata. Em segundo lugar, esse casamento entre capitalismo e democracia não é natural, pois, dentre outras coisas, ambos operam com formas contrárias de justiça. O capitalismo pratica uma justiça de mercado baseada no desempenho individual, enquanto a democracia se baseia na universalidade de direitos a partir da justiça social. Há, além disso, uma assimetria entre as duas justiças, já que o capital tem mais condições de reagir, podendo impor crises ao conjunto da população e justificar suas reivindicações como condições para o funcionamento do sistema como um todo. Já as reivindicações dos trabalhadores são vistas como perturbações e não como necessidades ao funcionamento do sistema.

Como último elemento distintivo da pista sob a qual o argumento de Streeck se desenvolve, vê-se a ideia de que, a partir do final dos anos 1960 e começo dos anos 1970, esse casamento forçado entre capitalismo e democracia começou a mostrar suas contradições através de crises que foram seguidamente adiadas de formas distintas até o momento atual. Com, principalmente, três fatores: a) a diminuição do crescimento econômico, antes constante e crescente; b) o clima político desenvolvido a partir das revoltas de 1968, a partir do qual alguns atores políticos, organizações de classe e intelectuais passaram a falar até mesmo na superação do mercado e do capitalismo; e c) a uma revalorização grande do mercado como instância de satisfação e gestão das mais diversas esferas da sociedade. Nesse período, a burguesia, acossada principalmente pelos dois primeiros fatores elencados acima e legitimada pelo terceiro fator, inicia a quebra do que fora duramente acordado por décadas e deixa de financiar essa forma de organização estatal voltada ao bem estar social. Desta feita, criticando a visão de autores como James Buchanan, Gordon Tullock e outros teóricos da chamada public choice, o Estado de Bem-estar social não 
teria chegado ao fim pela irresponsabilidade fiscal de trabalhadores que votariam pela maximização de seus bens e serviços de seu interesse, mas sim por uma escolha política deliberada dos capitalistas em geral.

Na sua introdução, intitulada "Teoria da crise - no passado e no presente", Streeck enuncia mais fortemente a sua filiação às teorizações da crise vindas da assim chamada Escola de Frankfurt, passando, de forma inespecífica, por Theodor Adorno, Max Horkheimer, Friedrich Pollock, Jürgen Habermas e Claus Offe. 0 essencial desta formulação sobre a crise, para o autor alemão, gira em torno de dois aspectos: i) o seu fundamento heurístico, desde o qual é possível ver uma tensão essencial entre a vida social civilizada e suas esferas e uma economia dirigida pelo imperativo de valorização do capital, que tende ao infinito e não possui freios normativos contra a barbarização; ii) o pressuposto de que o mais importante a ser estudado são os processos, em sua historicidade e em suas determinações basilares, e não os estados e momentos; de modo que aí as instituições sociais seriam vistas como engendradas pelo processo social, isto é, seriam provisórias, em permanente debate entre orientações políticas contraditórias e instáveis. Isso, a nosso ver, possibilitou um ponto de arrimo crítico interessante para Streeck, dado que, a partir dessa visão complexificada sobre a totalidade social em movimento, não caiu nas armadilhas da economia e da ciência política mainstream, confinadas ao individualismo metodológico e a uma operacionalização que isola o econômico e o político de outras esferas da vida (cf. Sartori, 2004; cf. Paulani, 2005). Não obstante, Streeck também faz críticas às teorizações frankfurtianas, pois, a seu ver, teriam acreditado demais na capacidade política de legitimação e planejamento do Estado e subestimado o poder do capital enquanto agente político e força social apta a desmobilizar e destroçar formas estatais específicas. Algo que, apesar de nosso acordo quanto a Habermas e Offe, é injusto com os frankfurtianos da chamada primeira geração, como mostraremos ao fim de nosso exercício de leitura crítica.

Já no primeiro capítulo do livro, Streeck repisa a sua crítica - apesar de reafirmar sua filiação - à teoria crítica frankfurtiana das crises, argumentando que esta teria se transformado em teorias da cultura, do Estado e da democracia, deixando de lado a crítica da economia política, achado essencial de Karl Marx - e boa parte de suas teorizações sobre, por exemplo, crescimento, subconsumo e superprodução. Contra isto, o autor alemão propõe que voltemos a olhar o capital como um agente econômico e político voltado à sua autovalorização constante e dotado de forte capacidade estratégica contra o que acha ser uma barreira contra seu desígnio maior: a acumulação. Deste modo, a construção de um capitalismo democrático, durante as chamadas três décadas de ouro após a Segunda Guerra Mundial, deveria ser vista como um momento muito específico no qual o capitalismo e os capitalistas estavam em baixa e aceitaram a fusão, tensa, com a democracia e com a melhoria 
constante do nível civilizacional da classe trabalhadora. Tudo isso fora aceito pelos agentes do capital como uma forma de reestruturação de sua legitimidade, bem como uma espécie de imposição pela luta entre as classes e não como mudança do ímpeto acumulativo do capital.

Esta crítica de Streeck às ideias de crise de legitimação frankfurtiana deságua num diagnóstico bastante instigante a respeito da crise desta forma de capitalismo democrático em meados da década de 1970, a saber: "não foram as massas que se recusaram a seguir o capitalismo do pós-guerra, acabando com ele, mas, sim, o capital sob a forma de organizações, organizadores e proprietários” (Streeck , 2018, p. 65). Porém, por que essa recusa se deu? Sobre este ponto, as explicações dadas pelo autor aparecem em momentos distintos do texto, o que pode causar certa confusão no(a) leitor(a); além disso, duas delas, ao menos aparentemente, são contraditórias - conforme exploraremos mais adiante. Todavia, Streeck aponta que três seriam as causas. Em primeiro lugar, teria ocorrido o início de certo achatamento da lucratividade do capital, devido, principalmente, aos custos com mão de obra, cada vez mais valorizada, e com os chamados encargos do Welfare State. Em segundo lugar, com as revoltas da década de 1960, mais especificamente, as de 1968, instaura-se um clima político entre segmentos específicos de forças sociais, políticas e intelectuais supostamente voltados à negação e superação do mercado e da mercadoria, deixando os capitalistas extremamente assustados. Em terceiro lugar, nessa mesma década de 1960, assiste-se a uma elevação inédita da legitimidade, em várias camadas da sociedade, das forças do mercado - vistas, neste período, como as melhores gestoras de diversas esferas da vida e da política - e ao aumento exponencial do consumismo e sua ideologia, conquistando novos domínios da vida social. Essa nova onda de legitimidade do mercado deu-se, num primeiro momento, a despeito das revoltas de 1968. Todavia, posteriormente, ela se deu utilizando-se, também, das pretensões emancipatórias dos manifestantes quanto à maior autonomia, à criatividade e à possibilidade de novas formas de vida distintas da família de classe média europeia e estadunidense. Deste modo, o desejo de autorrealização e flexibilidade comportamental e libidinal dos revoltosos de 1968 fora capturado por formas de trabalho e ocupação que embaralhavam termos opostos como independência e precariedade, conforme os diagnósticos de Boltanski e Chiapello (2009).

Outro lance argumentativo interessante de Streeck é quando liga a crise adiada - do capitalismo democrático de 1970 aos dias de hoje. De acordo com o nosso economista, tendo em vista os três elementos anteriores, pode-se notar o abandono dos capitalistas (ou dos dependentes do capital) do capitalismo democrático. Não obstante, esse abandono foi algo processual e não peremptório, dado que, ao mesmo tempo em que deveriam lograr a liberalização total da economia e de outras esferas da 
sociedade, não poderiam perder a sua legitimidade frente aos dependentes de salário em geral. Até porque, sem nenhum tipo de distribuição aos de baixo, o caminho para revoltas de todos os tipos estaria pavimentado. Streeck nota que, andando próximo àquela tendência de desacoplamento frente à regulação democrática, vê-se, entre as décadas de 1970 e 2010, uma contínua diminuição do crescimento econômico das economias centrais cada vez mais estagnadas. Tal diminuição do crescimento econômico fica sem maiores explicações e explicitações causais e de gênese por parte de Streeck - o que também criticamos ao final da resenha.

De toda forma, três seriam as formas de adiamento dos conflitos decorrentes da crise dos anos de 1970: i) inflação; ii) endividamento do Estado e iii) endividamento privado por meio da expansão dos mercados de créditos privados. Todos esses adiamentos, de um modo ou de outro, marcaram derrotas importantes para os assalariados e serão explorados por nós rapidamente - juntamente com as suas consequências para o povo dependente de salários e para a tentativa autoritária do mercado em se livrar de qualquer constrição da democracia.

A primeira forma de adiamento da crise se deu entre as décadas de 1970 e 1980 e foi materializada por meio da inflação. Isso se deu porque já nos anos de 1970 o pleno emprego, pedra angular da democracia no pós-guerra, passa a ser de difícil manutenção, dado que o crescimento econômico resultante do trabalho e do capital deixou de ser sistemático e ascensional. Assim, para evitar uma insatisfação popular generalizada com a não redistribuição dos lucros vindos da produção, o aumento salarial acima do aumento da produtividade fora sustentando por meio de uma política monetária de introdução “de recursos adicionais, que, no entanto, não estavam disponíveis senão sob a forma de dinheiro, não - ou ainda não - como algo real” (Streeck, 2018, p. 80). Gerando-se, desta feita, inflação. Mas não só. Essa ilusão monetária fora uma miragem de curto prazo, cujo fim fez com que investimentos diminuíssem ou fossem canalizados para outras moedas fora da zona econômica do atlântico norte. Já na metade da década de 1970, os agentes do capital, vendo tal situação de estagnação e inflação, colocaram na ordem do dia, sob a liderança de Reagan, nos Estados Unidos da América, e Thatcher, na Inglaterra, medidas de estabilização neoliberal drásticas. As quais foram um duro golpe nos dependentes de salários, visto que a deflação da economia foi decisiva para recessão e desemprego constantes. Condições importantes para a perda de poder dos sindicatos e da classe trabalhadora. Por conseguinte, a arena da disputa de classes, a partir deste momento, passa a se deslocar do mercado de trabalho e das fábricas, para lugares cada vez mais "abstratos" e inacessíveis ao cidadão comuns.

Essa política econômica "estabilizadora”, localizada no final dos anos 1970 e ao longo da década de 1980, mostrou-se uma porta de entrada importante, a um só tempo, para uma nova forma de adiamento da crise e de uma nova configuração 
estatal. Com a deflação anterior e o decréscimo no nível de vida, viu-se novamente o perigo da não legitimação do capitalismo tardio frente às camadas médias e populares, fazendo com que Estados e agentes econômicos fossem atrás de outra fonte de adiamento e legitimação, qual seja: o endividamento público. Ao modo da inflação, o endividamento público permite ao governo utilizar recursos financeiros provenientes do sistema monetário, mais especificamente do pré-financiamento de futuras receitas fiscais do Estado via instituições privada de crédito. Recursos que serão de suma importância para pacificação de conflitos sociais provenientes do crescente fosso entre as promessas do capitalismo e sua realização efetiva para a maioria da população. Outro movimento a que se assistiu, juntamente com esse endividamento do Estado, foi o de aumento dos créditos sobre os sistemas de seguridade social, em função, principalmente, da elevada taxa de desemprego e pelo fato de a moderação salarial da classe trabalhadora ter tido como termo de negociação o aumento de parcelas. Ou seja, politicamente, os governos não podiam nem cortar mais direitos do Estado Social nem aumentar impostos, dado que uma ou outra alternativa poderia cutucar onças com varas curtas; fazendo com que recorresse ao endividamento público.

Essa forma de adiamento fora tão sensível que se constitui como um pilar essencial da passagem do que Max Weber, Adolph Wagner, Richard Musgrave e Rudolf Goldscheide concebiam como Estado Fiscal, que expropriou sistematicamente e soberanamente os cidadãos em geral da sociedade civil, a fim de financiar o cumprimento de suas tarefas - como interferir no crescimento econômico, redistribuir riqueza e cobrir externalidades negativas do mercado -, para o Estado endividado. Este, para cumprir as suas tarefas e obrigações, passa a contrair empréstimos e deixa de cobrar uma taxa mais elevada de impostos daqueles que se apropriam da maior parte da riqueza socialmente produzida, os chamados dependentes do capital. Assim, Streeck pode afirmar, com dados e fatos, que a crise financeira não foi gerada pelas massas e suas demandas de civilidade, mas sim pelo andar de cima, que, década após década, viu seus rendimentos e propriedades, cada vez mais aumentados, serem cada vez menos taxados. Ou seja, numa movimentação unilateral de classe, deixaram de financiar o Estado social e o capitalismo democrático em prol da valorização do capital. Nesse bojo, a luta entre as classes também ganha outro contorno, passando a ser disputada dentro dos Estados de bem-estar social e não mais na produção, como anteriormente, girando em torno de disputas intraburocráticas e ainda mais distantes dos cidadãos dependentes do trabalho.

Nessa forma de Estado endividado, Streeck identifica propriamente uma nova fase de relação entre capitalismo e democracia. Isso se dá pelo fato de que, como o Estado passa a dever para instituições privadas de crédito, há sempre a desconfiança por parte destas de que o aparato estatal não honre as suas dívidas - apesar de ser 
um devedor deveras lucrativo e seguro -, o que faz com que os agentes do mercado passem cada vez mais a influenciar a política estatal com o intuito de assegurar seus lucros. Por conseguinte, os credores passam a ser uma espécie de segunda raiz constitutiva do Estado, de sorte que as políticas devem responder a dois setores ou povos distintos, a saber: a) o povo do Estado, composto por cidadãos nacionais, portadores de direitos civis, dependentes de serviços públicos, formadores da opinião pública e que expressam sua vontade eleitoral periodicamente - tudo isso em troca de lealdade ao Estado e ao pagamento de impostos; b) o povo do Mercado, formado por investidores - e não cidadãos - internacionalmente integrados, que visam exclusivamente a maximização de seus lucros e que se ligam ao primeiro povo apenas por contratos.

À vista deste quadro, o nosso autor tira algumas consequências importantes da relação entre capitalismo e democracia. Primeiro, o capital ou o povo do mercado deixou de influenciar a política apenas indiretamente, via investimento na economia, e passou para uma ação direta na política nacional ao escolher ou não financiar todo o Estado. Segundo, o povo do Estado, principalmente as camadas mais pobres, por resignação, comparecem cada vez menos às eleições, pois já não veem o que esperar de mudança do partido no governo, visto que a agenda política e econômica da esquerda e da direita pouco se diferenciam e passam a sofrer constrições decisivas do povo do mercado. Com isto, cada vez mais o capitalismo vai se blindando em relação à democracia e suas decisões e a transição neoliberal vai se estabilizando e se alastrando.

Na passagem da segunda para a terceira forma de adiamento da crise vê-se, além de uma nova forma de preterir a crise (o endividamento privado), a constituição de outra configuração estatal, ainda mais voltada aos interesses do capital e para consolidação do neoliberalismo. Já ao final dos anos 1980 e começo da década de 1990, iniciou-se um movimento dúplice: os governos passaram a se preocupar cada dia mais com o aumento do peso do serviço da dívida no orçamento e os credores, a cada dia que passava, desconfiavam da capacidade estatal para o pagamento das dívidas. Nesse período, sendo os EUA de Clinton a vanguarda do atraso, começaram cortes nos gastos sociais e tentativas de "equilibrar" o orçamento, prática seguida por várias outras nações e incentivada diretamente por organizações como Organização para Cooperação e Desenvolvimento Econômico (OCDE) e o Fundo Monetário Internacional (FMI). Apesar desse processo de liberalização radical dos mercados já vir de duas décadas anteriores, o capitalismo ainda precisava de uma forma de legitimação que, de uma só vez, mobilizasse recursos adicionais para evitar revoltas populares e não permitisse que a procura de capitais pelos países diminuísse, isto é, que a varinha de condão da confiança burguesa não deixasse de tocar as nações centrais. Para cumprir essas duas demandas, a saída da vez fora o endividamento privado, ou o que Colin 
Crouch chamou de "keynesianismo privado" (Crouch, 2009), injetando uma solvência antecipada no mercado numa segunda onda de liberalização dos mercados de capitais. Deste modo, substitui-se o endividamento público pelo endividamento privado como uma forma de aumentar as reservas disponíveis de recursos para distribuição. Nesse contexto, o papel do Estado mudou novamente, via liberalização do mercado de capitais no sentido de permitir o endividamento irrestrito dos agregados familiares, os quais tentam compensar tanto as perdas salariais de décadas, quanto a destruição das políticas estatais de desmercadorização.

Essa nova forma de adiamento forjou as bases para duas mudanças políticas e ideológicas importantes. Politicamente, vê-se a harmonização total entre a saída política encontrada e os desejos dos agentes do capitalismo neoliberal, harmonizando as necessidades e expectativas de ambos; até porque a desregulamentação das esferas da vida e dos mercados de capitais atingiu ali um nível nunca antes visto. Ideologicamente, operou-se um movimento dúplice: ao mesmo tempo em que surgiram novas teorizações a respeito da eficiência dos mercados desregulados, os quais contariam com agentes racionais que deteriam todas as informações necessárias para agir desde que o Estado não interferisse e desestabilizasse essa dinâmica, foram reabilitadas ideias de autores como o austríaco Friedrich Hayek, cuja proposição da transfiguração de todas as esferas da sociedade em empresas fora importante para imantar a prática de agentes capitalistas.

Nesse mesmo período, a formação estatal ganha outra conformação: passase do Estado endividado nacional para o Estado de consolidação internacional. Por consolidação, Streeck entende o crescente processo de consolidação do orçamento e das finanças públicas no sentido de restringir direitos e parcelas do Welfare State à população e permitir um ambiente seguro para as movimentações políticas e econômicas do povo do mercado. Desta feita, essa consolidação está intrinsecamente ligada a três outros movimentos importantes: i) redução do Estado ao mínimo funcional à expansão dos mercados, impedindo a intervenção estatal ativa no sentido de regular e mitigar a justiça de mercado; ii) institucionalização de uma economia política internacionalizada e a transformação dos Estados nacionais em entidades não soberanas ajustadas a uma política fiscal decidida por uma diplomacia internacional do capital, cujo ponto de fuga não é a civilidade e sim o da valorização do capital e iii) restrição da capacidade de ação e regulação democrática do povo do Estado, de forma a colocar na ordem do dia uma democracia desdemocratizada e domesticada pelas forças do mercado e não o contrário. Como o Estado de consolidação é um regime internacional, a própria luta distributiva atinge o seu maior nível de abstração e inacessibilidade aos estratos médios e popular, já que o poder passa a se concentrar numa diplomacia financeira internacional e em mercados de capitais blindados à intervenção democrática e política. 
Não obstante, em 2008, o keynesianismo privado veio abaixo. Essa forma de endividamento sustentou uma prosperidade enorme do setor financeiro e uma economia afluente, tudo isso sustentado pelo endividamento inaudito e colossal dos agregados familiares. Porém, a estrutura de crédito que permitia esse novo adiamento foi para os ares e o motivo era que todo aquele crédito liberado de modo algum poderia ser efetivamente saldado e boa parte do dinheiro em circulação, na forma de crédito, era fictício e lastreado em nada. Desta feita, os recursos para o adiamento da crise do capitalismo foram, um a um, testados e fracassaram, tornando qualquer saída cara demais para a diplomacia financeira internacional. À vista disto, o economista alemão vê duas alternativas possíveis: ou instaura-se realmente uma ordenação estatal neoliberal internacionalizada e pós-democrática, na qual o totalitarismo do mercado único sobrepujaria totalmente o povo do Estado, ou, a partir das mais variadas resistências populares - como o movimento global Occupy dos $99 \%$-, volta-se a pensar na reconsolidação de democracias nacionais capazes de reinstaurar instituições promotoras de uma justiça social não redutível à justiça do mercado, a exemplo do praticado durante o chamado consenso socialdemocrata, além da repactuação de um Bretton Woods necessário à manutenção da soberania e democracia nacionais. Desta feita, a alternativa pensada por Streeck passaria, necessariamente, pelas seguintes medidas: a) reaproveitamento e revitalização de instituições nacionais, ao modo de parlamentos, bancos centrais, canais de representações popular e instituições de seguridade social socialdemocratas, as quais representariam as diferenças entre os povos e as nações; b) o aumento do espaço de autonomia dos Estados nacionais frente às instituições globais de governança do povo do mercado e c) a reformulação de um acordo econômico europeu, feito Bretton Woods, desde o qual se repactuassem regras para relações econômicas, as quais resistissem ao avanço desenfreado da desregulamentação mercantil. Tendo isso em vista, poder-se-ia argumentar que isto é muito pouco perto do diagnóstico feito pelo próprio economista alemão. Todavia, o próprio Streeck nos adverte que todas essas medidas são formas de ganhar tempo contra a expansão capitalista desmedida e que soluções melhores e mais radicais de ação contra a desdemocratização neoliberal devem ser pensadas com urgência.

Apesar de ser um estudo com elementos e argumentos indispensáveis para compreensão do capitalismo contemporâneo, articulando de modo exemplar a relação entre economia, política e sociedade, algumas críticas podem ser tecidas ao estudo de Streeck, as quais dividimos em teóricas, geopolíticas e de encadeamento interno da exposição.

No primeiro grupo, nota-se uma leitura generalizante a respeito da chamada 
Escola de Frankfurt ou da teoria crítica, ${ }^{2}$ por dois motivos. Em primeiro lugar, a ideia de confiabilidade no caráter controlável do capitalismo, a partir da intervenção estatal e da democracia, é bem mais aplicável ao pensamento de Habermas - e, em menor medida, ao de Offe -, para quem o Estado democrático de direito teria plenas condições de domesticar o crescimento capitalista, de modo que os cidadãos teriam aí direitos políticos para tomar parte e direitos sociais de ter parte nos processos decisórios e redistributivos da sociedade (Habermas, 2015). Deste modo, o problema essencial a ser enfrentado é o da continuidade da legitimidade do compromisso em torno deste Estado e os possíveis problemas da intervenção estatal na vida das pessoas; assim, a saída seria apenas a repactuação em torno de arenas políticas e discursivas, para que o princípio da solidariedade e o mundo da vida tivessem condições de sobrepujar os imperativos sistêmicos. Em Adorno e Horkheimer, como podemos ver em vários momentos de suas obras, o poder de mudança regressiva do capital e da forma mercadoria não são deixados de lado em prol de "análises culturais". Mas sim que, partindo do diagnóstico pollockiano, poderíamos ver outros tipos de dominação menos imediatas determinadas - não em sentido fatalista - pela lógica da mercadoria (Fleck, 2016; Cook, 1998). Desta feita, a análise que fazem dos rackets não deixa dúvidas sobre a atenção que davam ao econômico e ao político (Adorno, 2003; Horkheimer, 2016). Ademais, se for permitido um reparo adorniano ao trabalho de Streeck, muito mais interessante que o uso da vaga ideia de ideologia do consumismo, seria lançar mão da noção de indústria cultural, dado que ela deveria ser entendida como uma continuação específica e crítica das teorizações sobre fetichismo e reificação de Marx e Lukács, de acordo com Adorno e Horkheimer (2006). Isso se dá porque o caráter de sistema da indústria cultural - composta pelo cinema, rádio, jazz, revistas, esporte, moda e livros de alta vendagem -, seria explicável justamente pela imposição do processo de reificação ao lazer e à cultura, impondolhes sua forma mercantil e tornando-as prolongamento do trabalho reificado. Forma reificada que condicionaria fortemente a apreensão da realidade, que passa a ser entendida agora como sistema imutável de leis especializadas e apreendida apenas pela contemplação, conformando uma individuação integrada à totalidade do capital e aos seus desígnios de consumo e manutenção do sistema.

Em segundo lugar, a teorização de Pollock surgiu em contraposição a outras duas. Uma, de origem social-democrata, propugnava a ideia de que as transformações do capitalismo no início do século XX apontavam para a sua estabilização; outra,

\footnotetext{
2 À primeira vista, esta crítica a Streeck pode parecer não essencial. Contudo, de acordo com argumento explorado posteriormente, caso o economista alemão tivesse dado maior consequência aos textos de Adorno e Horkheimer, poderia ter chegado a um diagnóstico e a uma crítica mais contundentes ao capitalismo contemporâneo e ao imbricamento ainda mais acentuado da tendência à reificação das subjetividades e ao poder destrutivo do capital, cujo cerne depõe contra o caráter facilmente controlável do capitalismo.
} 
aventada por figuras do comunismo ocidental, acreditava que estas transformações aprofundavam as contradições internas do capitalismo, apontando para seu colapso ou crise definitiva (Rugitsky, 2015). Contra ambas, Pollock $(1973 ; 1982)$ propõe que inexiste qualquer tendência inelutável de mudança ou colapso automático do capitalismo e que ele não estava passando por uma estabilização, mas sim por uma reestruturação na qual a primazia deixa de ser dos mecanismos do mercado e passa a ser do Estado, cuja política garante a reprodução da vida econômica.

À vista disto, pode-se entender a crítica de Streeck a certa "confiança" no planejamento mediante as reviravoltas do capital, porém é interessante que o economista alemão fale em greve de investimentos, em ação política das classes e na ideia de que as relações econômicas possuem uma fundamentação política, visto que isto não destoa de uma parte importante do diagnóstico de Pollock a respeito da politização do quadro institucional do capitalismo. E mais: o economista alemão havia pensado em duas possibilidades organizacionais para o capitalismo de Estado, o democrático e o autoritário; desta feita não poderíamos estar assistindo, na verdade, a passagem não para um Estado de consolidação, mas sim para um capitalismo de Estado autoritário? É preciso lembrar que o fato de a economia sofrer menos intervenções da democracia não quer dizer que a política saiu de cena, mas sim um tipo de política: a democracia de massas. Podendo restar aquilo que já era antevisto por Pollock, a saber: a força abismal dos dirigentes de grandes conglomerados e empresas, que, na esteira da monopolização acentuada decisivamente nos primórdios do século XX, passam a ser essenciais na vida social, política e econômica da população, pois, de um lado, o seu poder passa a se confundir com o poder estatal e, de outro, os seus prejuízos passam a ser socializados, dado que a sua falência causaria enorme impacto em toda a economia (Rugitsky, 2015, p. 63). Algo que, salvo engano, foi visto sistematicamente após a crise de 2008 em relação a variadas empresas e bancos, como Goldman Sachs e General Motors. Aspecto que poderia andar muito bem de mãos dadas com o processo de "desdemocratização do capitalismo por meio da deseconomização da democracia” (Streeck, 2018, p. 55).

Em relação à geopolítica, há duas ausências importantes na argumentação de Streeck: a primeira é a força da União Soviética e o contexto de Guerra Fria, a segunda são os processos de descolonização que assolaram o capitalismo central. Em relação ao primeiro fator, é possível dizer que a URSS, nas primeiras décadas do século XX, mostrou-se - independentemente de se gostar disto ou não - como uma alternativa de organização produtiva e social para a forte e organizada classe trabalhadora do centro e da periferia capitalista. Destarte, esses dois fatores um proletariado empoderado e dotado de uma alternativa de poder - produziram condições muito importantes para a consolidação de uma série de direitos sociais voltados para o bem-estar e para desmercadorização da população (Esping-Anderser, 
1991), ou, como dizia Francisco de Oliveira, os direitos do antivalor (1998). Tanto é que Buci-Glucksmann e Therborn (1981) chegaram mesmo a entender o Welfare State como uma espécie de revolução passiva, na qual as classes dominantes passam a acolher uma série de demandas dos trabalhadores, dado que estão pressionadas política e socialmente pela possibilidade real de uma Revolução.

Já quanto ao segundo elemento elencado, desde o final da Segunda Guerra Mundial e se arrastando pelas décadas de 1950 e 1970, é possível notar um importante processo de descolonização pelo mundo, o que necessariamente implicou na perda relativa de poder político e econômico sobre a periferia do capitalismo mundial, deixando os dependentes do capital nos países centrais preocupados com uma diminuição da lucratividade de atividades organizadas em torno de matérias primas das ex-colônias (Jameson, 1999; Visentini, 2012). Nesse bojo, é notável o caso da Organização dos Países Exportadores de Petróleo (OPEP), que passou a nacionalizar as reservas petrolíferas e regular seus preços, e que produziu - em represália ao apoio dos EUA a Israel na guerra do Yom Kippur - a chamada primeira crise do petróleo (Hobsbawn, 1995, p. 421-447). Com a qual, a partir do aumento proposital dos preços dos barris da referida commodity, a OPEP produziu consequências profundas nas economias centrais, cujos índices inflacionários bateram recordes, e que pode ter ajudado a acender o sinal amarelo das elites nacionais sobre os caminhos que o capitalismo democrático poderia traçar contra seus interesses de acumulação.

Ainda nessa seara, outro fato geopolítico importante, e que não aparece na explicação de Streeck, é a concorrência do que Araujo e Bresser-Pereira (2018) chamam de porções não-ocidentais do mundo no pós-Segunda Guerra Mundial. De acordo com estes autores, na esteira dos processos de globalização e descolonização, o que ocorreu não foi a destruição da forma política Estado-nação soberano, mas sim a sua dispersão e depuração mundial. Com isto, tais países alcançaram condições políticas e técnicas suficientes para controlar os recursos minerais de seus territórios e para dispor de um contingente enorme de mão de obra. Fatores que, combinados, passaram a exercer uma profunda pressão sobre os países desenvolvidos do centro ocidental do capitalismo, a qual "acabou afetando, a partir da década de 1970, o modo de legitimação dos Estados sob o chamado 'consenso socialdemocrata' dos anos dourados do capitalismo, os quais, após a Segunda Guerra Mundial, puderam oferecer cada vez melhores condições de vida às suas classes médias e populares" (Araujo; Bresser-Pereira, 2018, p. 556).

Desde o começo, salientou-se que a base sobre a qual o estudo de Streeck se concentra são os países desenvolvidos do centro do capitalismo, não obstante o fato de que considerações de economia geopolítica, como as que expomos, não fazerem parte de sua exposição acaba enfraquecendo seu argumento, dado que não se consegue explicar satisfatoriamente as determinações essenciais da estagnação 
do crescimento dos países centrais, por exemplo. À vista disso, partiremos para a exposição do que consideramos ser problemático no encadeamento expositivo interno do trabalho do economista alemão.

Conforme dissemos anteriormente, os anos de 1970 são chave para a passagem ao início de um adiamento tríplice da crise do capitalismo democrático e para o baixo crescimento econômico do que era antes o centro dinâmico do capitalismo no atlântico norte. No entanto, apesar da centralidade destes dois processos para o livro de Streeck, há três elementos que tornam essas passagens expositivas insatisfatórias. Em primeiro lugar, como já dissemos no início deste exercício de leitura, as três causas do início da crise adiada - a saber, o achatamento do lucro do capital no centro do capitalismo, a radicalização de alguns setores importantes contra a lógica mercantil e o prestígio da ideologia consumista - são expostas de forma disparatada no texto, sem maior imbricamento e coesão entre elas, obrigando o(a) leitor(a) a caçar estas explicações ao longo do livro. Prova disto é que, ao longo dos capítulos um e dois, nos quais ele se debruça sobre os momentos de passagem de um capitalismo democrática mais consolidado para os adiamentos de sua crise, poucas são as vezes em que, ao menos, duas das causas expostas acima sejam apresentadas conjuntamente, de modo que durante quase cinquenta páginas é necessário pinça-las no texto. Ademais, a sua apresentação conjunta e imbricada não se dá durante a argumentação do economista alemão.

Em segundo lugar, apesar de Streeck concentrar-se propositalmente nos países desenvolvidos do capitalismo, algumas determinações de seus insucessos econômicos e políticos devem ser buscadas fora deles. Isso não se coaduna com a ideia de que Streeck seria etnocêntrico ou coisa do gênero (cf. Cariello, 2019), mas, tão somente, pretende-se chamar atenção para uma das lições da crítica da economia política de Marx (1983) - reivindicada por Streeck contra as teorizações que esquecem das reviravoltas do capital: o fato de que o capitalismo é um sistema totalizante e que impõe a forma mercadoria e sua lógica em todos os cantos do globo e em todas as esferas da vida. Consequentemente, a exposição, mesmo concentrando-se nos países do centro do capitalismo, deveria prestar atenção em determinações que estão fora dele, pois, de acordo com outro ensinamento dos dialéticos, a primazia do método deve estar no objeto e suas implicações, as quais, no caso do capitalismo, são mundiais, queira-se ou não.

Em terceiro lugar, o economista alemão argumenta que haveria, em meados das décadas de 1960 e 1970, uma tendência contrária ao capitalismo e uma tendência que alargaria a sua legitimidade. À princípio, isto não seria em si problemático, porém a exposição do autor não deixa claro como esses dois termos se apresentam na realidade. A partir do que Streeck escreve, mas não desenvolve satisfatoriamente, poderíamos desdobrar a seguinte linha de raciocínio: ao mesmo tempo que segmentos 
específicos da sociedade, como parte dos trabalhadores, intelectuais e frações jovem e estudantis, tentavam colocar em xeque o sistema, gestou-se uma hegemonia ainda mais forte de legitimação mercantil, a qual enraizou-se de forma mais eficaz na sociedade. Ademais, essa tendência pró-capitalista pôde, ainda, apropriar-se de boa parte das bandeiras levantadas nos movimentos radicais de 1960 e 1970, convertendoas aos dogmas do capital, apesar de sua aparência libertária. Desta feita, a luta por formas de vida autônomas e contrárias ao poder da mercadoria, fora funcionalizada como engrenagem de um capitalismo mais, aparentemente, flexível e hype.

\section{Referências:}

Adorno, T. (2003). "Reflections on Class Theory". In: Tiedemann, Rolf (org.). Can One Live After Auschwitz? A Philosophical Reader. Stanford: Stanford University Press.

Adorno, T.; Horkheimer, M. (2006). Dialética do esclarecimento: fragmentos filosóficos. Rio de Janeiro: Jorge Zahar.

Araujo, C.; Bresser-Pereira, L. C. (2018). Para além do capitalismo neoliberal: as alternativas políticas. Dados, 61 (3), pp. 551-579.

Boltanski, L. e Chiapello, È. (2009). O novo espírito do capitalismo. São Paulo: Martins Fontes.

Buci-Glucksmann, C. e Therborn, G. (1981). Le défi social-démocrate. Paris: Maspero.

Cariello, R. (2019). Eurocentrismo à esquerda. Quatro cinco um: a revista dos livros. 1(20), pp 18.

Cook, D. (1998). Adorno on late capitalism. Totalitarianism and the Welfare State. Radical Philosophy, 1(89), pp. 16-26.

Crouch, C. (2009). Privatized Keynesianism: an unacknowledged policy regime. British Journal of Politics and International Relations, 1 (11), pp. 382-399.

Elbe, I. (2013). Between Marx, Marxism, and Marxisms - ways of reading Marx's theory. Viewpoint Magazine, 21 out. 2013. http://viewpointmag.com/2013/10/21/ between-marx-marxism-and-marxisms-ways-of-reading-marxstheory [acesso em 04.06.2020].

Esping-Andersen, G. (1991). As três economias políticas do Welfare State. Lua Nova, 2(24), pp. 85-116.

Fleck, A. (2016). Necessária, mas não suficiente: sobre a função da crítica da economia na teoria crítica tardia de Theodor W. Adorno. Cadernos de filosofia alemã, 21 (2), pp. 13-29.

Jameson, F. Periodizando os anos 60. (1999). In: Hollanda, H. B. Pós-modernismo e política. Rio de Janeiro: Rocco.

Kalecki, M. (1943), Political Aspects of Full Employment. Political Quartely, 1(14), pp. 322-331. 
Hobsbawn, E. (1995). A era dos extremos: o breve século XX. São Paulo: Companhia das Letras.

Horkheimer, M. (2016). On the Sociology of Class Relations. 2016. https://nonsite. org/the-tank/max-horkheimer-and-the-sociology-of-class-relations [acesso em 05.06.2020].

Marx, K. (1983). O capital: crítica da economia política, vol.1, tomo 1. São Paulo: Abril Cultural.

Oliveira, F. de. (1988). O surgimento do antivalor. Novos estudos, 3(22), pp. 8-28.

Paulani, L. (2005). Modernidade e discurso econômico. São Paulo: Boitempo editorial.

Piketty, R. (2014). O capital no século XXI. Rio de Janeiro: Intrínseca.

Polanyi, K. (2000). A grande transformação: as origens de nossa época. Rio de Janeiro: Campus.

Rugitsky, F. (2008). "Friedrich Pollock: limites e possibilidades". In: Nobre, Marcos (org.). Curso Livre de Teoria Crítica. Campinas: Papirus.

Sartori, G. (2004). Where Is Political Science Going? Ps: Political Science and Politics, Cambridge, 37 (4), pp. 785-787.

Streeck, W. (2018). Tempo comprado: a crise adiada do capitalismo democrático. São Paulo: Boitempo.

Visentini, P. F. (2012). As revoluções africanas: Angola, Moçambique e Etiópia. São Paulo: UNESP. 